\title{
Helen Salisbury: (I can't get no) patient satisfaction
}

\author{
Helen Salisbury GP \\ Oxford
}

The National Patient Satisfaction survey results were published in July: patients gave their opinions on reception teams, clinicians, and their overall experience of using their GP surgery. We've been judged, sorted, and ranked accordingly. That our surgery was rated highly suggests that we're managing to fulfil our patients' needs, but our own sense of satisfaction shouldn't distract from pointing out the problems inherent in this process. The local press was quick to hand out bouquets and brickbats, naming and shaming the practices that came low down in the survey. ${ }^{1}$ As the sample size is small-a few hundred surveys sent and about a hundred responses per practice-there's an element of luck about whether the angriest or most supportive patients respond. Despite this play of chance, which introduces some random variation, the results have a discernible pattern: practices in affluent, leafy areas of our county are generally rated more highly than those working with deprived populations. Should we believe that GPs working at the deep end are less kind, less caring, or less efficient? Perhaps we should instead consider why it's harder to provide the service needed in these areas. Our funding formula doesn't take account of deprivation. ${ }^{2}$ Not only do poorer people die earlier but the burden of ill health, and therefore the need for care, also occurs sooner. ${ }^{3}$ Funding is partly age based, but it doesn't recognise that a patient in his mid-50s in an economically deprived part of town may have the health needs of a 75 year old at my practice, but without the allocation of commensurate resources.

It's not surprising, then, that this presentation of the survey has prompted negative reactions from some GPs: "It's humiliating_kicking us when we're down"; "We're already working all hours and not seeing our kids, and what for?"

The latest government statistics tell us that health inequalities are getting worse and that overall life expectancy has fallen in the past five years. ${ }^{3}$ A later, more measured, piece in my local newspaper explores how these inequalities are playing out at a local level. ${ }^{4}$

Reducing health inequalities is a major component of the NHS long term plan, ${ }^{5}$ and NHS England urgently needs to consider how it supports and encourages hardworking GPs in deprived areas, who are the people most able to tackle this problem. Giving them inadequate resources to do the job and then berating them for falling short is not a recipe for high morale and indeed may force experienced GPs into early retirement.

Clearly, there's a benefit in learning from our patients about how we could improve our services, but, if the press translates this into yet another opportunity to bash GPs, it will do harm where help is most needed. In this way, Tudor Hart's inverse care law is perpetuated. ${ }^{6}$

Competing interests: See www.bmj.com/about-bmj/freelance-contributors. Provenance and peer review: Commissioned; not externally peer reviewed.

1 Grant P. BEST and WORST GP surgeries in Oxfordshire-as voted by patients. Oxford Mail 2019 Jul 28. https://www.oxfordmail.co.uk/news/17794681 .best-worst-gp-surgeriesoxfordshire---voted-patients/.

2 Levene LS, Baker R, Bankart J, Walker N, Wilson A. Socioeconomic deprivation scores as predictors of variations in NHS practice payments: a longitudinal study of English general practices 2013-2017. Br J Gen Pract 2019;69:e546-54.

10.3399/bjgp19X704549. 31208972

3 Office for National Statistics. Life expectancy and healthy life expectancy in England, by the Index of Multiple Deprivation 2015 (IMD15), 2015 to 2017. 27 Mar 2019. https://www. ons.gov.uk/peoplepopulationandcommunity/healthandsocialcare/healthinequalities/bulletins/ healthstatelifeexpectanciesbyindexofmultipledeprivationimd/2015to2017\#life-expectancyand-healthy-life-expectancy-in-england-by-the-index-of-multiple-deprivation-2015-imd152015-to-2017.

4 Oliver G. Wagstaff A. Life expectancy gap between Oxford's richest and poorest residents widens to 15 years. Oxford Mail 2019 Aug 6. https://www.oxfordmail.co.uk/news/17816451. life-expectancy-gap-oxford-39-s-richest-poorest-residents-widens-15-years/.

5 NHS. NHS long term plan. https://www.longtermplan.nhs.uk/.

$6 \quad$ Hart JT. The inverse care law. Lancet 1971;1:405-12. 10.1016/S0140-6736(71)92410-X. 4100731

Published by the BMJ Publishing Group Limited. For permission to use (where not already granted under a licence) please go to http://group.bmj.com/group/rights-licensing/ permissions 